\title{
The polypyrimidine tract binding protein is a monomer
}

\author{
TOM P. MONIE, ${ }^{1}$ HELENA HERNANDEZ, ${ }^{3}$ CAROL V. ROBINSON, ${ }^{3}$ PETER SIMPSON, ${ }^{2}$ \\ STEPHEN MATTHEWS, ${ }^{2}$ and STEPHEN CURRY ${ }^{1}$ \\ ${ }^{1}$ Division of Cell and Molecular Biology and ${ }^{2}$ Division of Molecular Biosciences, Imperial College London, London SW7 2AZ, \\ United Kingdom \\ ${ }^{3}$ Department of Chemistry, University of Cambridge, Cambridge CB2 1EW, United Kingdom
}

\begin{abstract}
The polypyrimidine tract binding (PTB) protein is a potent regulator of alternative mRNA splicing. It also participates in other essential cellular functions, including translation initiation and polyadenylation. Several published reports have suggested that the protein forms a dimer in solution, a feature that has been widely incorporated into mechanistic models of protein function. However, recent studies have provided indications that full-length PTB is a monomer. Here we present new biophysical and biochemical evidence supporting the monomeric status of the protein. By use of blue-native polyacrylamide gel electrophoresis and size-exclusion chromatography, PTB was observed as a single molecular species under native reducing environments, though in oxidizing conditions, a larger protein species was also detected. Further analyses of wild-type and mutant PTB molecules with SDS-PAGE and time-of-flight electrospray ionization mass spectroscopy confirmed these observations. They also identified the single reduced species as monomeric PTB and the higher-molecular-weight nonreduced species as disulphidelinked PTB dimer mediated by Cys23. Our results indicate that the use of oxidizing environments in previous studies is likely to have contributed to the misassignment of PTB as a dimer. Although purified PTB may form disulphide-linked dimers under these conditions, in the reducing intracellular environment the protein will be monomeric. These findings have implications for the construction of models of PTB function in regulating mRNA metabolism.
\end{abstract}

Keywords: polypyrimidine tract binding protein; PTB; monomer; disulphide; dimer

\section{INTRODUCTION}

The polypyrimidine tract binding protein (PTB) is an RNAbinding protein with an extensive repertoire of cellular roles. It has been demonstrated to play a crucial role in the negative regulation of alternative splicing, via the repression of exon inclusion, for a growing number of genes (see Izquierdo et al. 2005; Sharma et al. 2005; and references therein). Indeed, PTB has been shown to regulate its own alternative splicing (Wollerton et al. 2004). PTB also promotes translation initiation from a variety of viral (Hellen et al. 1993; Kaminski et al. 1995; Pilipenko et al. 2001) and cellular (Mitchell et al. 2001, 2005; Pickering et al. 2003) internal ribosome entry sites and is reported to regulate the polyadenylation (Luo 1999; Castelo-Branco et

\footnotetext{
Reprint requests to: Stephen Curry, Biophysics Section, Division of Cell and Molecular Biology, Imperial College London, South Kensington Campus, Room 746 Huxley Building, London SW7 2AZ, United Kingdom; e-mail: s.curry@imperial.ac.uk; fax: +44-20-7589-0191.

Article and publication are at http://www.rnajournal.org/cgi/doi/ 10.1261/rna.2214405.
}

al. 2004), localization (Cote et al. 1999), and stabilization (Knoch et al. 2004) of mRNA.

PTB contains four RNA recognition motifs (RRMs), the most common motif found in RNA-binding proteins (Maris et al. 2005). In PTB, both RRMs 1 and 4 display a classic $\beta \alpha \beta \beta \alpha \beta$ topology, while RRMs 2 and 3 possess a C-terminal extension incorporating a fifth $\beta$-strand, which enlarges the RNA-binding $\beta$-sheet surface (Conte et al. 2000; Simpson et al. 2004). Each RRM in PTB contributes to RNA binding, with specificity for short polypyrimidine sequences, although the protein has also recently been reported to associate with double-stranded RNA (Mitchell et al. 2005).

Initial investigations of the oligomerization state of PTB were interpreted as indicating that PTB is a homodimer in solution, with dimerization being postulated to result from interactions predominantly involving RRM2 (Perez et al. 1997; Oh et al. 1998). The assumption of homodimer formation was widely incorporated, both explicitly and implicitly, into models of PTB function (Wagner and GarciaBlanco 2001; Mitchell et al. 2003; Pickering et al. 2004). However, more recent analytical ultracentrifugation analy- 
sis of PTB and a range of recombinant subfragments suggest that the protein may in fact be monomeric (Simpson et al. 2004; Amir-Ahmady et al. 2005) and have therefore challenged the existing consensus on PTB dimerization. The methods used in these recent studies rely on an accurate determination of the PTB concentration, a nontrivial measurement given the low extinction coefficients of the constructs used (Simpson et al. 2004; Amir-Ahmady et al. 2005).

We report here new concentration-independent biochemical and biophysical analyses of wild-type and mutant PTB. Our results show that PTB dimerization only occurs in oxidizing conditions and is mediated by a single intermolecular disulphide bridge involving Cys23. This finding indicates that some of the previous reports of PTB dimerization are due to experiments being performed under oxidizing conditions. Under reducing conditions, which is the redox state relevant to the intracellular milieu, PTB is found to be monomeric.

\section{RESULTS}

\section{PTB dimerization requires an oxidizing environment}

Comparison of the range of published results on PTB oligomerization suggested that the assignment of PTB as a monomer or dimer might correlate with the use of reducing or oxidizing conditions in the experiment (Perez et al. 1997; Oh et al. 1998; Simpson et al. 2004). We therefore decided to investigate this possibility explicitly.

Blue native polyacrylamide gel electrophoresis (BNPAGE), a "charge shift" method of electrophoresis (Schagger et al. 1994), was used to determine the molecular mass and native oligomeric status of purified recombinant PTB1. In oxidizing conditions, both monomeric and dimeric forms were observed (Fig. 1, lane 1); no species larger than a dimer was identified. However, in a reducing environment, PTB1 dimerization was completely abrogated (Fig. 1, lane 2). Interestingly, the PTB1 monomer band appeared as a doublet in the absence of DTT but as a single band following reduction (Fig. 1, cf. lanes 1 and 2).

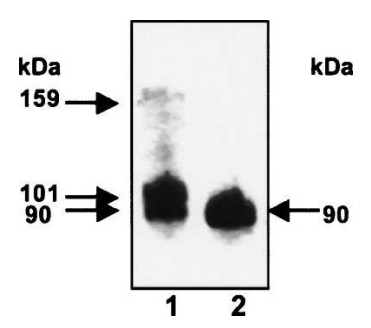

FIGURE 1. Blue-native polyacrylamide gel electrophoresis (BNPAGE). Ten micrograms of PTB1 was separated under native conditions using BN-PAGE. (Lane 1) Oxidizing environment, (lane 2) reducing environment $(+10 \mathrm{mM}$ DTT). Distinct protein bands are marked by arrows and their calculated molecular weight listed.

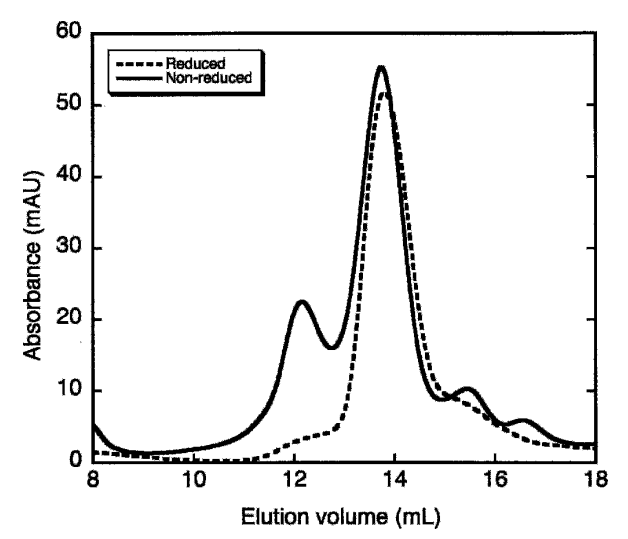

FIGURE 2. Size-exclusion chromatography of PTB1. Size-exclusion chromatography was performed on PTB1 under both oxidizing (solid line) and reducing conditions (dashed line). The estimated molecular weights of the elution peaks are labeled.

The apparent molecular weight of PTB1 was calculated from triplicate experiments using a linear plot of $M_{r}$ against electrophoretic migration of known protein standards (see Materials and Methods). The calculated molecular weights were as follows: PTB1 dimer, 159 $\mathrm{kDa}$; nonreduced PTB1 monomer, 101 and $90 \mathrm{kDa}$; and reduced PTB1 monomer, $90 \mathrm{kDa}$. While these values are larger than are the theoretical masses (monomer, 58,316 Da; dimer, $116,633 \mathrm{Da}$ ), the monomeric values are broadly consistent with those obtained previously by using size-exclusion chromatography (Simpson et al. 2004). It is likely that that the molecular mass is overestimated by this technique due to the extended rod-shaped structure of PTB1, which was revealed by small-angle X-ray scattering (Simpson et al. 2004).

We next used size-exclusion chromatography to examine PTB oligomerization. Under reducing conditions (2 mM DTT), PTB1 eluted with an apparent molecular weight in the region of $100 \mathrm{kDa}$, with minimal additional protein signal outside this major peak (Fig. 2, dotted line; Simpson et al. 2004). This is likely to correspond to monomeric PTB given the asymmetric shape of the protein. In the absence of any reducing agent, although most of the protein eluted at $\sim 100 \mathrm{kDa}$, the peak was significantly broader and a second elution peak was observed at a predicted molecular mass of $239 \mathrm{kDa}$ (Fig. 2, solid line). This elution profile is broadly consistent with that obtained under oxidizing conditions by Perez et al. (1997). The 239-kDa peak observed in our elution under oxidizing conditions is presumably due to disulphidelinked dimers and probably corresponds to the protein shoulder previously observed at $\sim 200 \mathrm{kDa}$ (Perez et al. 1997). The predicted mass of this dimer peak is over twice that of the eluted monomeric protein and suggests that formation of an intermolecular disulphide bridge does not lead to a more compact, globular protein conformation. 


\section{Cys23 mediates intermolecular disulphide bridge formation}

The change in oligomeric profile for PTB1 upon variation in reducing environment provided strong evidence that the observed dimers resulted from intermolecular disulphide bridge formation. PTB contains three cysteines: at residue 23 , in the N-terminal sequence preceding RRM1, and at residues 250 and 251 within RRM2. The N-terminal sequence of PTB is likely to be flexible since it is proteolytically sensitive (Simpson et al. 2004), and Cys23 is therefore potentially accessible for participation in disulphide bridges. The three-dimensional structure of RRM2 (PDB ID 1sjr) reveals that Cys250 and Cys251 are found close to the protein surface at the C-terminal end of the loop between helix- 2 and strand $\beta 4$ (Simpson et al. 2004). Although Cys251 appears inaccessible to solvent, Cys250 is partially surface-exposed and may also be able to participate in disulphide bridge formation.

To clarify whether PTB could form disulphide bridgemediated dimers, site-directed mutagenesis was used to generate the mutant constructs PTB1-C23S and PTB1C250S/C251S. The formation of disulphide-mediated dimers was assayed by SDS-PAGE using either an oxidizing or a reducing sample loading buffer. Under reducing conditions, wild-type PTB1 and both mutants (PTB1-C23S, PTB1C250S/C251S) migrated solely as monomers (Fig. 3, lanes 13). In contrast, in an oxidizing environment, both PTB1 and PTB1-C250S/C251S migrated at sizes consistent with the presence of both monomer and dimer (Fig. 3, lanes 4,6). However, PTB1-C23S remained entirely monomeric (Fig. 3, lane 5). These results clearly demonstrated not only that PTB1 can form disulphide-mediated dimers but that these are mediated solely through intermolecular interactions involving Cys 23 .

The lack of formation of intermolecular disulphide bonds by cysteines C250 and C251 within RRM2 is consistent with the observation by NMR that they readily form an intramolecular connection. When exposed to oxidizing conditions (either the absence or the depletion of $10 \mathrm{mM}$

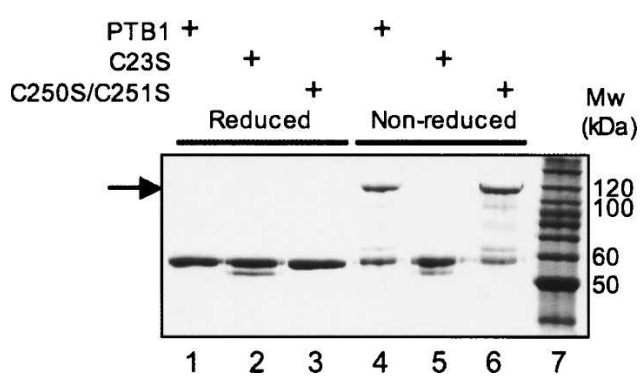

FIGURE 3. SDS-PAGE analysis of PTB1 and cysteine mutant derivatives. One microliter of $10 \mu \mathrm{M}$ protein samples was analyzed in either reducing (lanes 1-3) or oxidizing (lanes 4-6) environments. (Lanes 1,4) PTB1, (lanes 2,5) PTB1-C23S, (lanes 3,6) PTB1-C250S/C251S, (lane 7) Benchmark protein ladder (Invitrogen). The arrow indicates the presence of disulphide-mediated dimers.

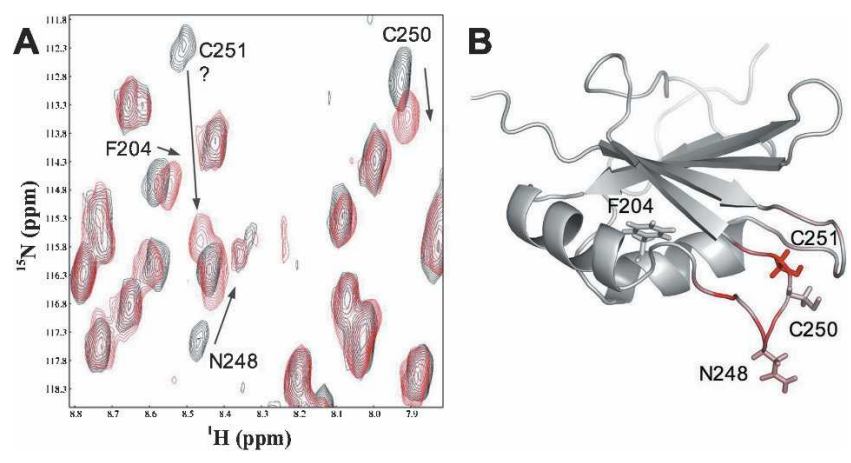

FIGURE 4. NMR analysis of intramolecular disulphide formation by $\mathrm{C} 250$ and C251. (A) Expanded region from the two-dimensional ${ }^{1} \mathrm{H}^{-}{ }^{15} \mathrm{~N}$ HSQC spectrum of PTB RRM2 domain in the presence (black) and the absence (red) of $10 \mathrm{mM}$ reduced DTT. Some residues exhibiting a change in chemical shift upon oxidation are labeled. A question mark indicates the presumed shift of C251, which was not determined unambiguously. $(B)$ Cartoon representation of PTB RRM2. Residues associated with significant shifts in $A$ are shown in a stick representation (side chains only). The structure is colored according to the change in chemical shift upon oxidation (gray, no shift; pink, small shift; red, large shift). The figure was generated using Pymol (DeLano Scientific).

DTT), chemical shift changes are observed in both cysteines and also in residues immediately adjacent in the structure, which are entirely consistent with disulphide bond formation (Fig. 4A,B). The chemical shift changes are reversible by the addition of fresh reducing agent and are not accompanied by any change in NMR line width, indicating that the domain remains monomeric. Together these data indicate that the cysteine residues in RRM2 readily form an intramolecular disulphide bond.

To probe the oligomerization state of PTB and the impact of the Cys residues under more native conditions, we used nanospray ElectroSpray Ionisation Mass Spectrometry (ESI-MS), a technique that is well adapted to the analysis of both covalent and noncovalent protein-protein interactions (Hernandez and Robinson 2001; Hanson and Robinson 2004). In particular, we compared the oligomerization states of wild-type PTB1, the PTB1-C23S mutant, and PTB1-1234, a truncated construct that lacks the first 54 amino acids (and therefore lacks Cys23). Proteins were analyzed at a concentration of $10 \mu \mathrm{M}$ in $50 \mathrm{mM}$ ammonium acetate ( $\mathrm{pH} 6.5)$.

Under oxidizing conditions, analysis of PTB1 identified mass/charge peaks consistent with the presence of both monomeric $(58,328 \pm 7 \mathrm{Da})$ and dimeric species $(116,661 \pm 15 \mathrm{Da})$ (Fig. 5A). For the monomer, two conformations were indicated by the presence of two charge state distributions in the spectra. Increasing instrument pressure in the source/transfer region, thereby favoring noncovalent dimer formation, produced minimal detectable changes in the observed spectra. In addition, MS/MS analysis failed to dissociate the PTB1 dimer peaks into monomers, even with increasing collision energy (data not shown). However, the presence of $5 \mathrm{mM}$ DTT eliminated 


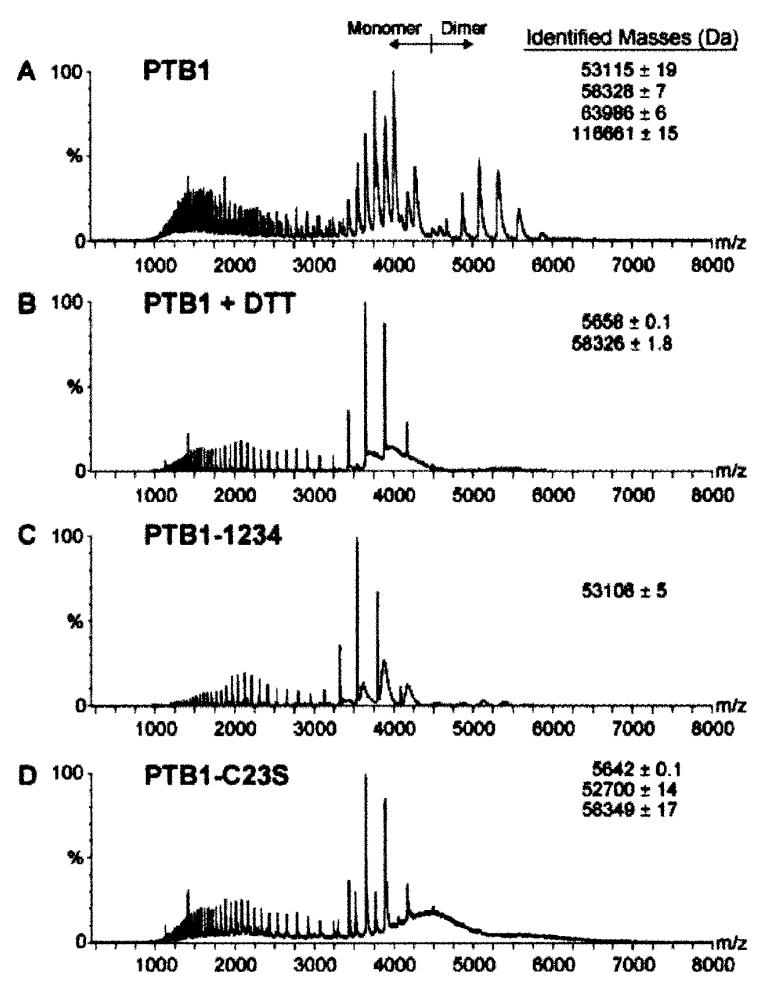

FIGURE 5. Electrospray ionization mass spectroscopy analysis of PTB proteins. Samples containing $2 \mu \mathrm{L}$ of $10 \mu \mathrm{M}$ protein in $50 \mathrm{mM}$ ammonium acetate ( $\mathrm{pH}$ 6.5) were analyzed by nanospray electrospray ionization mass spectroscopy under native conditions using a modified QToF2 instrument fitted with a standard Z-spray nanoflow electrospray source. The mass/charge peaks were identified using MassLynx, and the corresponding masses are listed to the right of each panel. (A) PTB1, $(B)$ reduced PTB1 (buffer supplemented with 5 mM DTT), (C) PTB1-1234, (D) PTB1-C23S.

the dimer peaks; it also resulted in the appearance of a peak at $5.7 \mathrm{kDa}$, most likely a minor proteolytic contaminant (Fig. 5B). The presence of dimers could not be restored with increasing pressure.

To confirm that these dimers were disulphide mediated, we performed ESI-MS analysis of the constructs PTB1-1234 and PTB1-C23S, in which Cys23 has been deleted and mutated, respectively. Only monomeric protein could be identified for PTB1-1234 (53,108 \pm 5 Da) and PTB1-C23S $(58,349 \pm 17 \mathrm{Da})$ under both oxidizing (Fig. 5C,D) and reducing (data not shown) conditions. Together these data strongly indicate that the PTB1 dimers formed in oxidizing conditions are the result of covalent disulphide interactions between the cysteine residue at position 23 on each protein molecule.

\section{DISCUSSION}

This report provides new biophysical and biochemical evidence that PTB exists as a monomer in solution, confirming recent findings derived from analytical ultracentrifugation experiments with PTB (Simpson et al. 2004; Amir-Ahmady et al. 2005). Moreover, in conjunction with results from NMR and small-angle X-ray scattering experiments (Simpson et al. 2004), the present observations provide an explanation for the previous misconception that PTB exists as a homodimer in solution. Firstly, the asymmetrical rod-shaped conformation of PTB1 leads to a significant overestimation of the molecular weight of PTB monomers when native gels or size-exclusion techniques are used. Secondly, we have shown that although PTB dimers can form under oxidizing conditions, these are entirely due to the formation of an intermolecular disulphide bridge involving Cys 23 on both partners. We suggest that both of these factors contributed to the apparent observation of PTB dimerization in previous analyses of PTB oligomerization, which used gel filtration chromatography, in vitro pull-down assays, nondenaturing PAGE, and glutaraldehyde cross-linking, and were all performed under oxidizing conditions (Perez et al. 1997; Oh et al. 1998). In experiments performed under reducing conditions (Figs. 1, 2, 3, 5), PTB behaved as a monomer; we found no evidence for noncovalent dimerization.

In vitro pull-down assays (Perez et al. 1997) and glutaraldehyde cross-linking experiments (Oh et al. 1998) using recombinant PTB fragments lacking Cys 23 provided evidence for self-association of PTB that cannot be attributed to the formation of disulphide bridges and led to the suggestion that RRM2 mediated noncovalent association of PTB monomers. However, in these studies, the self-association behavior was principally observed for constructs in which RRM2 was located either at the $\mathrm{N}$ or the $\mathrm{C}$ terminus of the truncated protein, an exposed position that is not found in full-length PTB. Subsequent analyses using both NMR and analytical ultracentrifugation have shown that these types of fragment aggregate nonspecifically (Simpson et al. 2004).

The formation of disulphide-mediated PTB dimers cannot account for self-association behavior deduced from yeast two-hybrid experiments (Oh et al. 1998), since the reducing environment of the yeast nucleus would have prevented disulphide bridge formation. However, it remains possible that the apparent PTB-PTB interaction observed by this technique could have been mediated by interactions with other proteins or with RNA. Yeast twohybrid data need to be supported by more direct analyses of protein-protein interactions, but the balance of the data now suggests that PTB is indeed monomeric.

Until recently it has been widely accepted that human PTB exists as a homodimer in solution. It is now apparent that under reducing conditions PTB exists as a monomer and that this is the physiologically relevant state of the protein in the reducing environment of the cell. This study provides a revealing example of the care that needs to be taken in determining the oligomeric state of intracellular proteins. The findings will also help to clarify analyses of the likely stoichiometry of PTB-RNA complexes and the formulation of models of PTB function. Of course, it remains possible that multimers of $\mathrm{PTB}$ will form when 
the protein associates with RNA targets or other proteins in vivo (Chou et al. 2000; Polydorides et al. 2000; Huttelmaier et al. 2001; Amir-Ahmady et al. 2005).

\section{MATERIALS AND METHODS}

\section{Plasmid construction and protein expression}

The plasmids PTB1 (residues 1-531) and PTB1-1234 (residues 55531) expressing human PTB have been described previously (Simpson et al. 2004). Mutant constructs PTB1-C23S and PTB1C250S/C251S were created by QuikChange site-directed mutagenesis of PTB1 using the following primer pairs, in which the mutated codons are underlined: C23S, GACGAGCTCTTCTCTA CTAGTGTCACTAACGGACC and GGTCCGTTAGTGACACTA GTAGAGAAGAGCTCGTC; C250S/C251S, AGAACATCTACAAC GCCTCCTCCACGCTGCGCATC and GATGCGCAGCGTTGGA GGAGGCGTTGTAGATGTTCT. Mutations were confirmed by sequencing. Proteins were expressed essentially as described (Conte et al. 2000) by using SG13009 cells and were purified by using TALON (Clontech) affinity resin.

\section{BN-PAGE}

BN-PAGE analysis was performed based on the method of Schagger and von Jagow (1991) using $10 \mu \mathrm{g}$ of protein in $20 \mathrm{mM}$ Tris (pH 7.7), $200 \mathrm{mM} \mathrm{NaCl}$, and $10 \%$ glycerol. To create a reducing environment, this was supplemented with $10 \mathrm{mM}$ DTT. Electrophoresis was performed by using prefocused $\left(100 \mathrm{~V}, 60 \mathrm{~min}, 4^{\circ} \mathrm{C}\right)$ $4 \%-15 \%$ Tris- $\mathrm{HCl}$ gradient gels (Biorad) for $2-4 \mathrm{~h}$ at $15 \mathrm{~mA}$ and $4^{\circ} \mathrm{C}$. The cathode buffer was $50 \mathrm{mM}$ Tricine, $15 \mathrm{mM}$ BisTris- $\mathrm{HCl}$ ( $\mathrm{pH} 7.0$ ), and $0.02 \%(\mathrm{w} / \mathrm{v}$ ) Coomassie blue G; the anode buffer, 50 $\mathrm{mM}$ BisTris- $\mathrm{HCl}$ ( $\mathrm{pH} 7.0$ ). To enhance final visualization of protein bands, gels were completely destained $(40 \% \mathrm{EtOH}, 10 \%$ acetic acid) and then restained (50\% EtOH, 10\% acetic acid, 0.1\% [w/v] Coomassie blue). A linear plot of $\mathrm{M}_{\mathrm{r}}$ against distance migrated was obtained for each gel by using the following proteins: $\beta$-amylase $(200 \mathrm{kDa})$, alcohol dehydrogenase and its dissociated subunits $(150 \mathrm{kDa}$ and $50 \mathrm{kDa})$, HSA monomer and disulphide-linked dimer (66 kDa and $132 \mathrm{kDa})$, and chicken albumin (45 kDa).

\section{SDS-PAGE}

One microliter of $10 \mu \mathrm{M}$ protein stocks was subjected to standard electrophoresis in 12\% SDS-polyacrylamide gels using both reducing and nonreducing sample loading buffers. Two times reducing sample loading buffer is $125 \mathrm{mM}$ Tris- $\mathrm{HCl}$ (pH 6.8), $2 \%$ SDS, $20 \%$ glycerol, $0.02 \%$ Bromophenol blue, and $730 \mathrm{mM} \beta$-mercaptoethanol. Oxidizing sample loading buffer did not contain $\beta$-mercaptoethanol. Samples were not boiled prior to electrophoresis.

\section{Size-exclusion chromatography}

Size-exclusion chromatography was performed as described previously (Simpson et al. 2004) by using either a reducing $(25 \mathrm{mM}$ Tris at $\mathrm{pH} 7.2,250 \mathrm{mM} \mathrm{NaCl}, 2 \mathrm{mM}$ DTT), or a nonreducing (25 $\mathrm{mM}$ Tris at $\mathrm{pH} 7.2,250 \mathrm{mM} \mathrm{NaCl}$ ) buffer.

\section{NMR spectroscopy}

Two-dimensional ${ }^{1} \mathrm{H}_{-}{ }^{15} \mathrm{~N}$ NMR spectra were recorded at $303 \mathrm{~K}$ on a $500-\mathrm{MHz}$ four-channel Bruker DRX500 spectrometer equipped with a $\mathrm{z}$-shielded gradient triple resonance cryoprobe. Samples of reduced ${ }^{15} \mathrm{~N}$-labeled PTB1 RRM2 were $\sim 100-200 \mu \mathrm{M}$ (pH 6.5) in $50 \mathrm{mM} \mathrm{Na}$ phosphate buffer, $150 \mathrm{mM} \mathrm{NaCl}, 10 \mathrm{mM}$ DTT, and 1 $\mathrm{mM} \mathrm{NaN}$. Spectra of oxidized protein were acquired both by allowing samples containing DTT to oxidize in air and by preparing fresh protein in identical buffer but with the omission of DTT. Chemical shift changes upon oxidation were judged significant by using a weighted sum of $10\left(\Delta \delta^{\mathrm{H}}\right)+\Delta \delta^{\mathrm{N}}$ (ppm) as described previously (Simpson et al. 1999).

\section{Time-of-flight electrospray ionization MS}

For analysis under native conditions, purified protein was buffer exchanged into $50 \mathrm{mM}$ ammonium acetate ( $\mathrm{pH}$ 6.5) and diluted to a final concentration of $10 \mu \mathrm{M}$ in $50 \mathrm{mM}$ ammonium acetate (pH 6.5). Spectra were also recorded on samples supplemented with 2-5 mM DTT. Data were acquired by using a modified QToF2 instrument (Waters) fitted with a standard Z-spray nanoflow electrospray source. Sample solutions were sprayed from borosilicate glass capillaries ( $1 \mathrm{~mm}$ outer diameter $\times 0.5 \mathrm{~mm}$ inner diameter) that had been drawn down to a closed taper using a Model P-97 Flaming/Brown micropipette puller (Sutter Instrument) and coated with gold using a SEM coater (Polaron). The tapered end of the capillary was cut under a microscope. A low backing pressure of nitrogen gas was used to initiate and maintain flow through the capillary. All data were acquired in positive ion mode using a nitrogen cone gas flow to aid desolvation. Throttling of the source rotary pump was used to control instrument pressures for collisional cooling. Spectra were acquired with the following parameters: capillary voltage, $1.8 \mathrm{kV}$; cone voltage, $200 \mathrm{~V}$; extractor voltage, $0 \mathrm{~V} ; 1 \times 10^{-2}$ mbar indicated source pressure; and $6.9 \times 10^{-7}$ mbar indicated ToF analyser pressure. All data were processed by using MassLynx software, and cesium iodide solution was employed for calibration.

\section{ACKNOWLEDGMENTS}

This work was funded by grant support from the Wellcome Trust.

Received August 15, 2005; accepted September 21, 2005.

\section{REFERENCES}

Amir-Ahmady, B., Boutz, P.L., Markovtsov, V., Phillips, M.L., and Black, D.L. 2005. Exon repression by polypyrimidine tract binding protein. RNA 11: 699-716.

Castelo-Branco, P., Furger, A., Wollerton, M., Smith, C., Moreira, A., and Proudfoot, N. 2004. Polypyrimidine tract binding protein modulates efficiency of polyadenylation. Mol. Cell. Biol. 24: 4174-4183.

Chou, M.Y., Underwood, J.G., Nikolic, J., Luu, M.H., and Black, D.L. 2000. Multisite RNA binding and release of polypyrimidine tract binding protein during the regulation of c-src neural-specific splicing. Mol. Cell 5: 949-957.

Conte, M.R., Grune, T., Ghuman, J., Kelly, G., Ladas, A., Matthews, S., and Curry, S. 2000. Structure of tandem RNA recognition motifs 
from polypyrimidine tract binding protein reveals novel features of the RRM fold. EMBO J. 19: 3132-3141.

Cote, C.A., Gautreau, D., Denegre, J.M., Kress, T.L., Terry, N.A., and Mowry, K.L. 1999. A Xenopus protein related to hnRNP I has a role in cytoplasmic RNA localization. Mol. Cell 4: 431-437.

Hanson, C.L. and Robinson, C.V. 2004. Protein-nucleic acid interactions and the expanding role of mass spectrometry. J. Biol. Chem. 279: 24907-24910.

Hellen, C.U., Witherell, G.W., Schmid, M., Shin, S.H., Pestova, T.V., Gil, A., and Wimmer, E. 1993. A cytoplasmic 57-kDa protein that is required for translation of picornavirus RNA by internal ribosomal entry is identical to the nuclear pyrimidine tract-binding protein. Proc. Natl. Acad. Sci. 90: 7642-7646.

Hernandez, H. and Robinson, C.V. 2001. Dynamic protein complexes: Insights from mass spectrometry. J. Biol. Chem. 276: 46685-46688.

Huttelmaier, S., Illenberger, S., Grosheva, I., Rudiger, M., Singer, R.H., and Jockusch, B.M. 2001. Raver1, a dual compartment protein, is a ligand for $\mathrm{PTB} / \mathrm{hnRNPI}$ and microfilament attachment proteins. $J$. Cell. Biol. 155: 775-786.

Izquierdo, J.M., Majos, N., Bonnal, S., Martinez, C., Castelo, R., Guigo, R., Bilbao, D., and Valcarcel, J. 2005. Regulation of Fas alternative splicing by antagonistic effects of TIA-1 and PTB on exon definition. Mol. Cell 19: 475-484.

Kaminski, A., Hunt, S.L., Patton, J.G., and Jackson, R.J. 1995. Direct evidence that polypyrimidine tract binding protein (PTB) is essential for internal initiation of translation of encephalomyocarditis virus RNA. RNA 1: 924-938.

Knoch, K.P., Bergert, H., Borgonovo, B., Saeger, H.D., Altkruger, A., Verkade, P., and Solimena, M. 2004. Polypyrimidine tract-binding protein promotes insulin secretory granule biogenesis. Nat. Cell Biol. 6: 207-214.

Luo, G. 1999. Cellular proteins bind to the poly(U) tract of the $3^{\prime}$ untranslated region of hepatitis C virus RNA genome. Virology 256: 105-118.

Maris, C., Dominguez, C., and Allain, F.H. 2005. The RNA recognition motif, a plastic RNA-binding platform to regulate post-transcriptional gene expression. FEBS J. 272: 2118-2131.

Mitchell, S.A., Brown, E.C., Coldwell, M.J., Jackson, R.J., and Willis, A.E. 2001. Protein factor requirements of the Apaf-1 internal ribosome entry segment: Roles of polypyrimidine tract binding protein and upstream of N-ras. Mol. Cell. Biol. 21: 3364-3374.

Mitchell, S.A., Spriggs, K.A., Coldwell, M.J., Jackson, R.J., and Willis, A.E. 2003. The Apaf- 1 internal ribosome entry segment attains the correct structural conformation for function via interactions with PTB and unr. Mol. Cell 11: 757-771.

Mitchell, S.A., Spriggs, K.A., Bushell, M., Evans, J.R., Stoneley, M., Le Quesne, J.P., Spriggs, R.V., and Willis, A.E. 2005. Identification of a motif that mediates polypyrimidine tract-binding protein-dependent internal ribosome entry. Genes \& Dev. 19: 1556-1571.

Oh, Y.L., Hahm, B., Kim, Y.K., Lee, H.K., Lee, J.W., Song, O., Tsukiyama-Kohara, K., Kohara, M., Nomoto, A., and Jang, S.K. 1998.
Determination of functional domains in polypyrimidine-tractbinding protein. Biochem. J. 331: 169-175.

Perez, I., McAfee, J.G., and Patton, J.G. 1997. Multiple RRMs contribute to RNA binding specificity and affinity for polypyrimidine tract binding protein. Biochemistry 36: 11881-11890.

Pickering, B.M., Mitchell, S.A., Evans, J.R., and Willis, A.E. 2003. Polypyrimidine tract binding protein and poly $\mathrm{r}(\mathrm{C})$ binding protein 1 interact with the BAG-1 IRES and stimulate its activity in vitro and in vivo. Nucleic Acids Res. 31: 639-646.

Pickering, B.M., Mitchell, S.A., Spriggs, K.A., Stoneley, M., and Willis, A.E. 2004. Bag-1 internal ribosome entry segment activity is promoted by structural changes mediated by poly $(\mathrm{rC})$ binding protein 1 and recruitment of polypyrimidine tract binding protein $1 . \mathrm{Mol}$. Cell. Biol. 24: 5595-5605.

Pilipenko, E.V., Viktorova, E.G., Guest, S.T., Agol, V.I., and Roos, R.P. 2001. Cell-specific proteins regulate viral RNA translation and virus-induced disease. EMBO J. 20: 6899-6908.

Polydorides, A.D., Okano, H.J., Yang, Y.Y., Stefani, G., and Darnell, R.B. 2000. A brain-enriched polypyrimidine tract-binding protein antagonizes the ability of Nova to regulate neuron-specific alternative splicing. Proc. Natl. Acad. Sci. 97: 6350-6355.

Schagger, H. and von Jagow, G. 1991. Blue native electrophoresis for isolation of membrane protein complexes in enzymatically active form. Anal. Biochem. 199: 223-231.

Schagger, H., Cramer, W.A., and von Jagow, G. 1994. Analysis of molecular masses and oligomeric states of protein complexes by blue native electrophoresis and isolation of membrane protein complexes by two-dimensional native electrophoresis. Anal. Biochem. 217: 220-230.

Sharma, S., Falick, A.M., and Black, D.L. 2005. Polypyrimidine tract binding protein blocks the $5^{\prime}$ splice site-dependent assembly of U2AF and the prespliceosomal E complex. Mol. Cell 19: 485-496.

Simpson, P.J., Bolam, D.N., Cooper, A., Ciruela, A., Hazlewood, G.P., Gilbert, H.J., and Williamson, M.P. 1999. A family IIb xylanbinding domain has a similar secondary structure to a homologous family IIa cellulose-binding domain but different ligand specificity. Structure Fold. Des. 7: 853-864.

Simpson, P.J., Monie, T.P., Szendroi, A., Davydova, N., Tyzack, J.K., Conte, M.R., Read, C.M., Cary, P.D., Svergun, D.I., Konarev, P.V., et al. 2004. Structure and RNA interactions of the N-terminal RRM domains of PTB. Structure (Camb.) 12: $1631-1643$.

Wagner, E.J. and Garcia-Blanco, M.A. 2001. Polypyrimidine tract binding protein antagonizes exon definition. Mol. Cell. Biol. 21 3281-3288.

Wollerton, M.C., Gooding, C., Wagner, E.J., Garcia-Blanco, M.A., and Smith, C.W. 2004. Autoregulation of polypyrimidine tract binding protein by alternative splicing leading to nonsense-mediated decay. Mol. Cell 13: 91-100. 

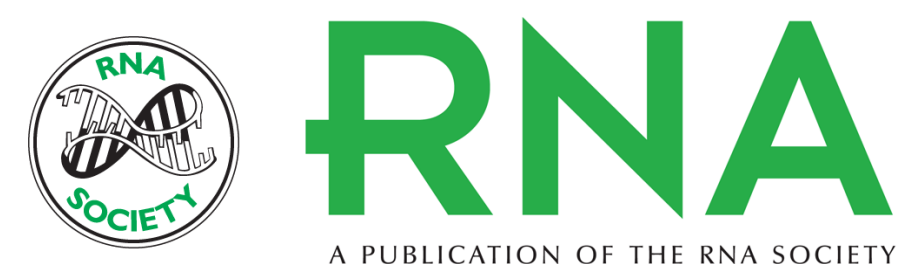

A PUBLICATION OF THE RNA SOCIETY

\section{The polypyrimidine tract binding protein is a monomer}

TOM P. MONIE, HELENA HERNANDEZ, CAROL V. ROBINSON, et al.

RNA 2005 11: 1803-1808

References This article cites 28 articles, 14 of which can be accessed free at:

http://rnajournal.cshlp.org/content/11/12/1803.full.html\#ref-list-1

License

Email Alerting Receive free email alerts when new articles cite this article - sign up in the box at the Service top right corner of the article or click here.

To subscribe to $R N A$ go to:

http://rnajournal.cshlp.org/subscriptions 